\title{
Environmental Sustainability of the Iron and Steel Industry: Towards Reaching the Climate Goals
}

\author{
Volodymyr Shatokha ${ }^{1}$
}

\begin{abstract}
Radical modernization of the greenhouse gas emitting industrial sectors is indispensable for transition to a low-carbon economy. The iron and steel industry accounts for $6.7 \%$ of the global anthropogenic carbon dioxide emissions. Futures of iron and steel industry based on various market penetration scenarios for best available and innovative technologies have been modelled and analyzed against the climate change mitigation targets identified by the International Energy Agency for keeping the global warming within $2^{\circ} \mathrm{C}$. Plausible modernization pathways have been studied revealing a possibility of achieving the levels of $\mathrm{CO}_{2}$ emissions consistent with the climate targets by 2030-2040. However, reaching of the targets established for 2050 requires disruptive innovations in a synergy with carbon capture and storage/utilization, enhanced material efficiency and greater share of recycled steel production. The need for international collaboration to facilitate development and commercialisation of eco-innovations has been revealed. International instruments shall be applied in order to deliver incentive for modernisation, to boost carbon investment mechanisms and to ensure borderless technology transfer.
\end{abstract}

\section{Introduction}

During the Paris Climate Change Conference in December 2015 governments worldwide have agreed that international climate policy should aim to limit the increase of global mean temperature to less than $2{ }^{\circ} \mathrm{C}$ with respect to pre-industrial levels. Achievement of this goal requires reducing significantly the greenhouse gases (GHG) emissions in all spheres of human activity. The EU has pledged at least a 40\% domestic reduction in GHG emissions by 2030 compared to 1990 levels (European Commission, 2015). The iron and steel industry accounts for $6.7 \%$ of the global anthropogenic and $31 \%$ of industrial $\mathrm{CO}_{2}$ emissions (Worldsteel, 2015; IEA, 2014). In the EU this sector accounts for $21 \%$ of total industrial $\mathrm{CO}_{2}$ emissions (Croezen and Korteland, 2010). Therefore cutting $\mathrm{CO}_{2}$ emissions in the iron and steel industry is indispensable for reaching the climate change mitigation goals.

A 2 Degrees Scenario (2DS) of the International Energy Agency (IEA, 2014) describes an energy system consistent with an emissions trajectory that would give an $80 \%$ chance of limiting average global temperature increase to $2^{\circ} \mathrm{C}$. It sets $28 \% \mathrm{CO}_{2}$ emissions reduction target for the global iron and steel sector in 2050 compared to 2011. This reduction shall happen under conditions of at least 51\% steel production growth within the same period, whereas, historically, production growth has always been coupled with increasing of the GHG emissions. This challenge is demonstrated in Fig.1 where statistic data for steel production and $\mathrm{CO}_{2}$ emissions (Worldsteel, 2014) are shown together with 
2DS targeted trajectories of the same. Business as usual $\mathrm{CO}_{2}$ emissions pathway (BAU projection of emission intensity observed in 2014) is also shown demonstrating a contradiction between the 2DS and historically observed trend. A 2DS trajectory for $\mathrm{CO}_{2}$ emissions was calculated using emissions intensity trend derived by (Krabbe et al, 2015). For steel production a low demand variant of the IEA 2DS model (IEA, 2014) was taken as a basis.

Decoupling of the GHG emissions from the production growth cannot be achieved based on current technologies, therefore the IEA scenario relies on a number of measures such as deployment of best available technologies (BAT), commercialisation of currently developed innovative technologies and Carbon Capture \& Storage/Utilization (CCS/CCU). In this paper a potential of these measures for decoupling the $\mathrm{CO}_{2}$ emissions from production growth and for reaching the climate change mitigation targets has been studied.

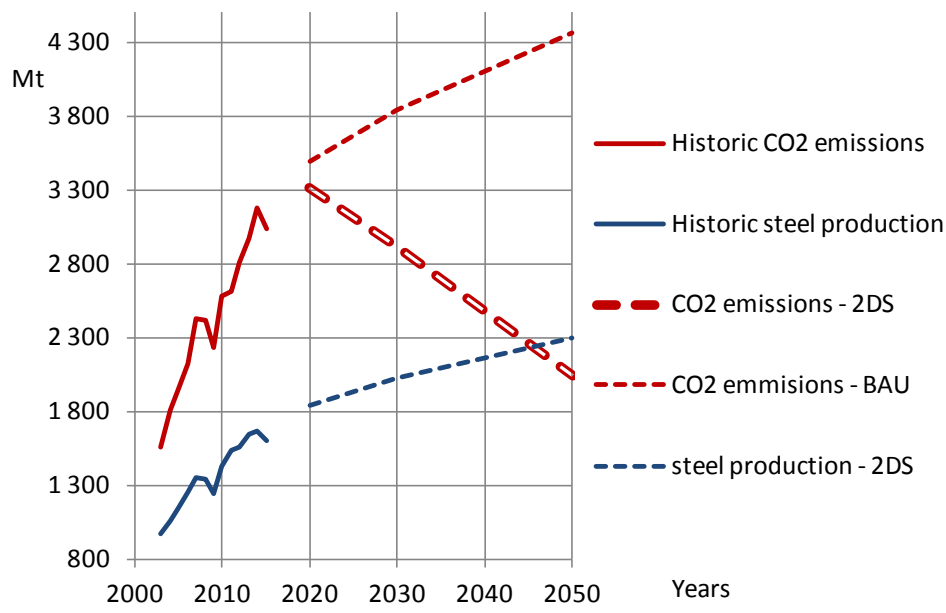

Fig.1 Historic trends, 2DS targeted and Business as Usual (BAU) trajectories for steel production and CO2 emissions.

\section{Methodology}

\subsection{Steel production routes}

Table 1 summarises the state-of-the-art for current technologies used to produce crude steel - a semi-product in a form of a billet or an ingot that shall be further processed to obtain saleable products. For the simplicity reasons some technologies with small market share are not shown. For the same reason some other materials and energy carriers (limestone, air, oxygen, oil, electricity) as well as the by-products (slag, gases) are also omitted in this table. 
Table 1: Steel production routes (BOF - basic oxygen furnace, EAF - electric arc furnace, NG Natural gas)

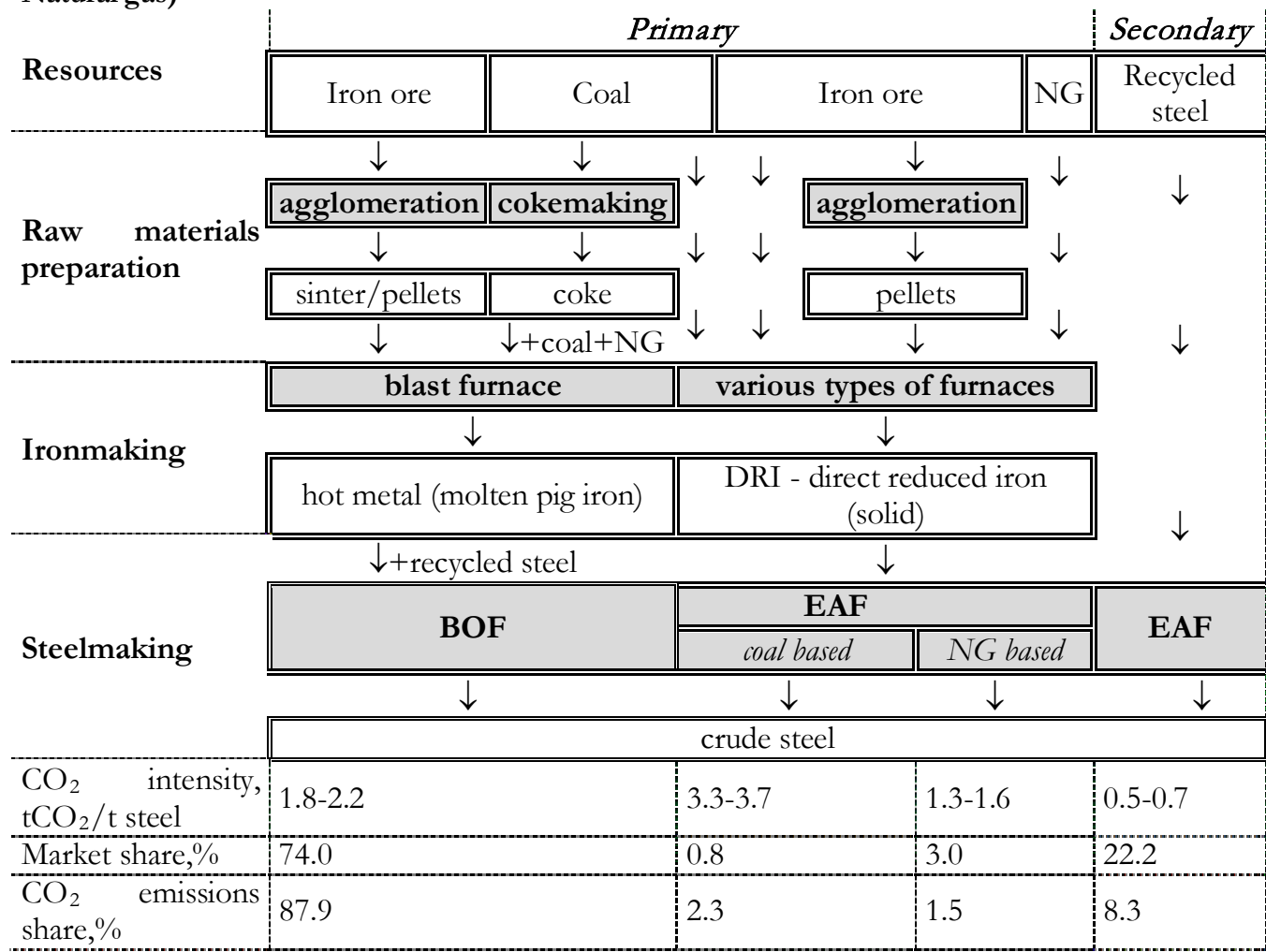

Production of steel from the scrap (recycled steel) consumes less energy and therefore emits less $\mathrm{CO}_{2}$ compared to primary steel route. However, current and future steel demand cannot be covered with scrap available.

Primary steel production route where blast furnace is used to produce molten semiproduct (pig iron), although being exploited for several centuries, still dominates owing to superior economic efficiency of blast furnaces, especially when it comes to high production volumes such as $1 \mathrm{Mt}$ per year or more. Carbon dioxide emissions are inevitable for any primary steel production technology because fossil fuels are used both to reduce iron from the oxides and to deliver the energy required by the processes.

With respect to infrastructural peculiarities of the steel sector demonstrated in Table 1 and owing to the fact that the blast furnace itself consumes nearly a half of primary energy needed to produce steel (Gutowski et al, 2013), substantial cutting of carbon dioxide emissions in iron and steel industry might be achieved through:

- improvement of energy efficiency through deployment of the BAT;

- increased share of recycled steel production;

- development of new and rapid commercialisation of currently developed innovative ironmaking technologies;

- deployment of the CCS/CCU. 


\subsection{Best Available Technologies (BAT)}

Nearly $95 \%$ of $\mathrm{CO}_{2}$ generated in primary steel production is sourced by the fossil fuels (the rest owes to the limestone decomposition) therefore energy saving is proportional to $\mathrm{CO}_{2}$ cutting. During the last 55 years energy consumption per tonne of steel produced has been reduced by $60 \%$ and for the advanced enterprises there is a little room to further improve energy efficiency on the basis of existing technologies (Worldsteel, 2015). However, for the individual steel producers a potential to cut energy consumption varies in a wide range. The specific energy saving values potentially achievable through deployment of the BAT by the worlds top steel producing countries are shown in Fig 2. For Japan, South Korea, Europe (OECD) and the US it is limited within 1-2 GJ per tonne of steel, whereas for China and Ukraine it exceeds 6 GJ per tonne. This variety relates to such factors as industry's infrastructure, conditions of the equipment, BAT penetration, quality of raw materials etc. The yearly energy saving potential, also demonstrated in Fig 2, shows immense importance of China in reducing the global energy consumption (China produces almost a half of the global steel output).

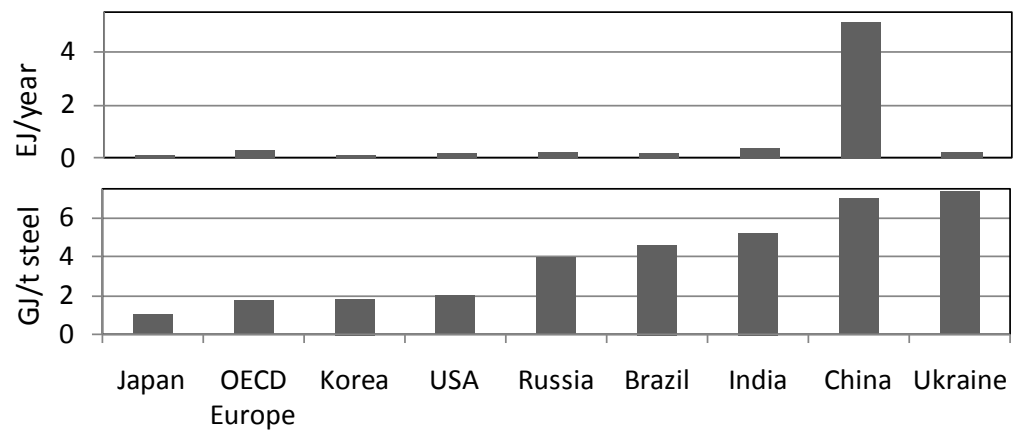

Fig.2 Energy savings potential of the BAT (in GJ/t steel and EJ/year) for the world's major steel producing countries (derived using the IE $A$ data (IE $A, 2014)$ )

The IEA estimates that $\mathrm{CO}_{2}$ emissions can be reduced through the BAT deployment by $19 \%$ compared to 2010 . In our model we use this figure $(19 \%)$ for estimating potential $\mathrm{CO}_{2}$ emissions reduction achieved by 2050. We assume that BAT penetration will follow S-curve with 2025 taken as the year of rapid penetration growth and 2050 as the year of saturation.

\subsection{Innovative technologies}

Several innovative technologies are being developed worldwide aiming to improve or substitute a blast furnace. The modern blast furnace is very efficient technology; however, being unsuitable for top charging of fine ore and coal, it requires well prepared raw materials - coke (coal thermal processing product) and sinter or pellets (agglomerated iron ore materials). Cokemaking and sintering/pelletizing are energy intensive. Therefore main directions of $\mathrm{R} \& \mathrm{D}$ in the field are: 
- delivery of an innovative smelter capable to produce the hot metal directly from iron ore and coal as well as from the industrial wastes;

- capturing of $\mathrm{CO}_{2}$ from a blast furnace top gas and recycling the remainder gas mixture back to a blast furnace.

In or study we consider four key technologies (all of them are part of 2DS) that owing to available information might be commercialised by 2025 or earlier.

Top Gas Recycling Blast Furnace (TGR) is one of the key technologies initiated in EU-funded ULCOS project (ULCOS, 2014). It implies separation of $\mathrm{CO}_{2}$ from the top gas and injection of remaining gas mixture $\left(\mathrm{CO}+\mathrm{N}_{2}+\mathrm{H}_{2}\right)$ back into blast furnace. TGR might be an option for both new enterprises and for retrofitting. Technological aspects were worked out at an experimental LKAB blast furnace in Luleo, Sweden. With recirculation ratio of $90 \%$, coke consumption was down by $25 \%$ which corresponds to cutting $24 \%$ of $\mathrm{CO}_{2}$. However, blast furnace top gas, being a by-product fuel with calorific value of c.a. $4 \mathrm{MJ} / \mathrm{m}^{3}$, is important component of energy mix at an integrated steelwork, hence its complete recycling is not economically feasible. Reduction of $\mathrm{CO}_{2}$ emissions by $15 \%$ per tonne of final product with limited top gas recycling ratio is considered in the paper (van der Stel, 2013) and this benchmark is taken in our analysis.

Pilot industrial implementation of this technology was planned in 2015 at ArcelorMittal Florange (France); however, in 2013 the project has been suspended owing to financial issues. Currently it is being continued in frames of the Low Impact Steelmaking project funded by ArcelorMittal and French government, but a timeline for its commercialisation is unclear. Similar technology is being developed also in Japanese state and privately funded COURSE 50 project (Tonomura, 2013), but its future is unclear as well.

HIsarna is a reduction-smelting technology that combines the Cyclone Converter Furnace (CCF) and the Smelt Reduction Vessel (SRV). The CCF has been developed by then Hoogovens company in 1990-s with pilot plant processing 15-20 t of iron ore per hour. Iron ore and oxygen were injected into the cyclone with burning a gas mixture. The product is the molten partially reduced ore with temperature of $1450{ }^{\circ} \mathrm{C}$.

The SRV pilot plant - HIsmelt (High Intensity Iron Smelting) - with capacity of $2 \mathrm{t}$ of hot metal per hour was launched in Maxhutte (Germany) in 1980-s. A larger (8 t/hour) pilot plant was then erected in Kwinana (Australia) and scaled up to a demonstration plant with capacity of $0.80 \mathrm{Mt} /$ year, launched in 2005 and operated till the end of 2008 as the result of collaboration between Rio Tinto, Nucor Corporation, Mitsubishi Corporation and Shougang Corporation (Rio Tinto, 2016). During financial crisis HIsmelt was relocated to China. Commissioning of Chinese $0.5 \mathrm{Mt} /$ year HIsmelt plant was planned in 2014, though we found no information concerning the current status of this project.

In Europe HIsarna, a hybrid of the CCF and HIsmelt, is being developed by Tata Steel in Ijmuiden (The Netherlands) as the part of the former ULCOS project in collaboration with Rio Tinto and several other steelmaking and engineering companies such as ArcelorMittal, ThyssenKrupp Stahl, voestalpine Stahl and Paul Wurth. In 2012-2015 HIsarna pilot plant ( $8 \mathrm{t}$ /hour) underwent a series of campaigns reaching $88 \%$ of initially designed productivity in a long term manner. Demonstration shall be finished by 2018 with further up-scaling and commercialisation after 2020 (Meijer et al, 2015). HIsarna 
generates more $\mathrm{CO}_{2}$ than a blast furnace but thanks to phasing out of cokemaking and sintering, the aggregate $\mathrm{CO}_{2}$ emissions are $20 \%$ lower compared to conventional primary steelmaking (Croezen and Korteland, 2010).

$F I N E X$ is the ironmaking technology developed by South Korean POSCO in collaboration with Siemens VAI. Its prototype, Corex, had two parts - a shaft furnace for iron ore pre-reduction and a melter-gasifyer. Its commercialisation started in 1989 but was limited only by South Africa and India because Corex is less energy efficient than a blast furnace.

FINEX project was initiated in 1992. In contrast to Corex, a shaft furnace is substituted by a cascade of fluidized bed reactors to heat up and to pre-reduce the ore. A briquetting machine is used to compact pre-reduced ore and coal thus enabling usage of low grade and fine raw materials. Laboratory installation (15 t/day) was up-scaled tenfold to a pilot plant in 1999. In 2003 a demonstration plant with capacity of $0.6 \mathrm{Mt} /$ year has been erected, followed by launching in 2007 of the first commercial plant with capacity of 1.5 Mt/year in 2007 at Pohang Works. More advanced FINEX plant with simplified design and capacity of $2 \mathrm{Mt}$ /year was launched in January 2014. The best result achieved corresponds to $97 \%$ of average fuel consumption in a blast furnace (combined with cokemaking and iron ore agglomeration). It is expected that better process control will help to reach in the nearest future the level of $90 \% \mathrm{CO}_{2}$ emissions compared to blast furnace (Yi and Lee, 2015). This benchmark is taken in our model.

\subsection{Scenarios}

In our study, similarly to 2DS, we optimistically assume that low-carbon technologies will be cost-effective and that barriers associated with regulatory frameworks and social acceptance will be overcome. Another assumption, used in 2DS, is that by 2050 electricity mix will depend on fossil fuels just for $20 \%$ (was $70 \%$ in 2011). In our model, we also consider decreasing of $\mathrm{CO}_{2}$ emissions in the recycling steelmaking route by $50 \%$, reaching $0.35 \mathrm{tCO}_{2} / \mathrm{t}$ steel in 2050 .

The overall share of the EAF in the global steel production from both recycled steel and DRI increases in 2DS to $37 \%$ by 2025 - 11\% up from 2014 level. However, with respect to the global development trends observed in steelmaking during last 15 years, we consider this target too optimistic. In our model, as it is shown in Fig 3, the EAF share in global steel production follows the S-curve, reaching the $37 \%$ target five years later than envisaged by the IEA and arriving to $40 \%$ in 2050 .

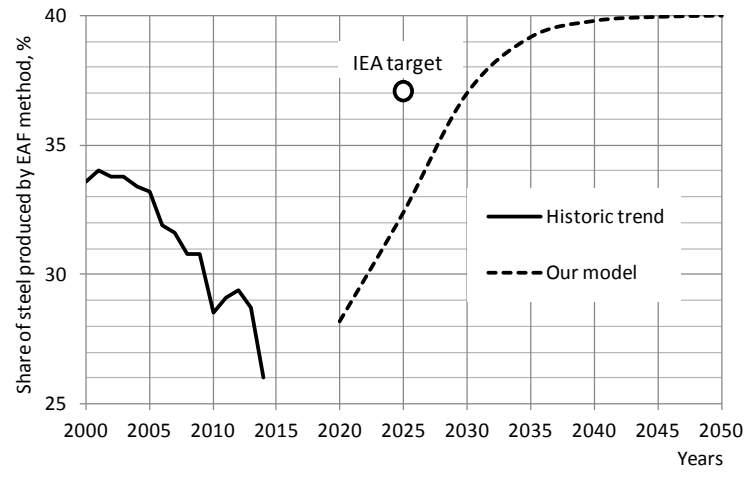

Fig. 3. Share of steel produced by the EAF method 
In our model we assume that the share of steel produced from the DRI manufactured using natural gas remains almost stable (3.1\% in 2050 against 3.0\% in 2014), whereas emissions intensity will be halved $\left(0.7 \mathrm{tCO}_{2} / \mathrm{t}\right.$ steel in 2050 against $1.4 \mathrm{tCO}_{2} / \mathrm{t}$ steel in 2014). We also assume that, owing to carbon constraints, the coal-based DRI manufacturing will be eliminated by 2050. Change of market share and reduction of the emissions intensity follow the S-curve.

Our scenarios are summarised in Table 2 and described below as follows:

- Scenario 1 implies global deployment of the BATs. Steel production structure remains the same: the share of the EAF method is limited at a current level $(26.0 \%)$. FINEX attains limited commercialisation gaining $1 \%$ of the primary iron production market; no other alternative ironmaking technology enters the market.

- Scenario 2 in addition to Scenario 1 assumes greater availability of scrap resulting in 40\% of steel produced in the EAFs $(36.9 \%$ in recycling-EAF route and $3.1 \%$ in DRI-EAF route) in 2050.

- Scenario 3 in addition to Scenario 2 envisages moderate penetration of alternative ironmaking technologies to the market. All molten pig iron produced distributes by processes as follows: $65 \%$ will be produced in conventional blast furnaces, $5 \%$ - in the TGR blast furnaces, 20\% in HIsarna and 10\% in FINEX.

- Scenario 4 is the most radical: in addition to Scenario 2 all remaining blast furnaces are modernised to produce just $5 \%$ of total molten pig iron - all with TGR, $85 \%$ of total molten pig iron is produced in HIsarna and 10\% in FINEX.

Table 2: Market shares of production technologies in the modelled scenarios

\begin{tabular}{|c|c|c|c|c|c|c|}
\hline \multirow{3}{*}{\multicolumn{2}{|c|}{ Production technologies }} & \multicolumn{5}{|c|}{ Global market share, $\%$} \\
\hline & & \multirow{2}{*}{2014} & \multicolumn{4}{|c|}{2050} \\
\hline & & & \begin{tabular}{|l} 
Scenario 1 \\
cenate
\end{tabular} & Scenario 2 & Scenario 3 & Scenario 4 \\
\hline \multirow{4}{*}{$\begin{array}{l}\text { Ironmaking } \\
\text { technologies }\end{array}$} & $\mathrm{BF}$ & 100 & 99 & 99 & 65 & 0 \\
\hline & TGR BF & 0 & 0 & 0 & 5 & 5 \\
\hline & HIsarna & 0 & 0 & 0 & 20 & 85 \\
\hline & Finex & $\approx 0$ & 1 & 1 & 10 & 10 \\
\hline \multicolumn{2}{|c|}{ EAF steelmaking } & 26.0 & 26.0 & 40 & 40 & 40 \\
\hline \multicolumn{2}{|c|}{ BOF steelmaking } & 74.0 & 74.0 & 60 & 60 & 60 \\
\hline
\end{tabular}

\section{Results and discussion}

Possibilities to reduce $\mathrm{CO}_{2}$ emissions in the scenarios concerned in relationship to the IEA target are shown in Fig. 4. Even global deployment of the BAT in the Scenario 1 is far not sufficient for approaching the IEA target. However, increased production of steel from scrap in the EAF (in case if electricity generation is decarbonised as planned) in Scenario 2 changes the situation drastically - by 2030 the IEA target can be reached; however, not in a long term manner: market gradually saturates with the BAT and emissions deviate from the IEA curve starting from 2035. In Scenario 2 specific emissions reach the level of $1.22 \mathrm{tCO}_{2} / \mathrm{t}$ steel by 2050 instead of 0.89 planned by IEA.

Secondary steel production depends upon scrap availability. Comprehensive study 
(Pauliuk et al, 2013) demonstrates a possibility to produce up to half of steel from scrap by 2050 . Nevertheless, we have to admit that plausibility of climate change mitigation scenarios is very sensitive to availability of scrap. In fact developed economies usually accumulate essential quantity of "to be scrapped" metal, whereas in the developing countries, after they reach certain industrialisation level, the primary steel production route usually dominates - simply because the quantity of scrap available do not satisfy the needs of growing economy. The quality of secondary steel is inherently lower than of primary one, being another constraining factor for increased recycling, but analysis of this factor is beyond the scope of current work.

Limited deployment of alternative ironmaking technologies in Scenario 3 only slightly improves the result achievable in Scenario 2: deviation from the IEA target is delayed by 2-3 years and the emission intensity decreases to $1.16 \mathrm{tCO}_{2} / \mathrm{t}$ steel in 2050 .

Most radical modernisation with global deployment of alternative ironmaking technologies in Scenario 4 allows even for exceeding the IEA targets during 2030-2044. However, after that market is saturated with new technologies and achievable emission intensity again deviates from the IEA target reaching the level of $1.02 \mathrm{t}$ of $\mathrm{CO}_{2}$ per tonne of crude steel in 2050 .

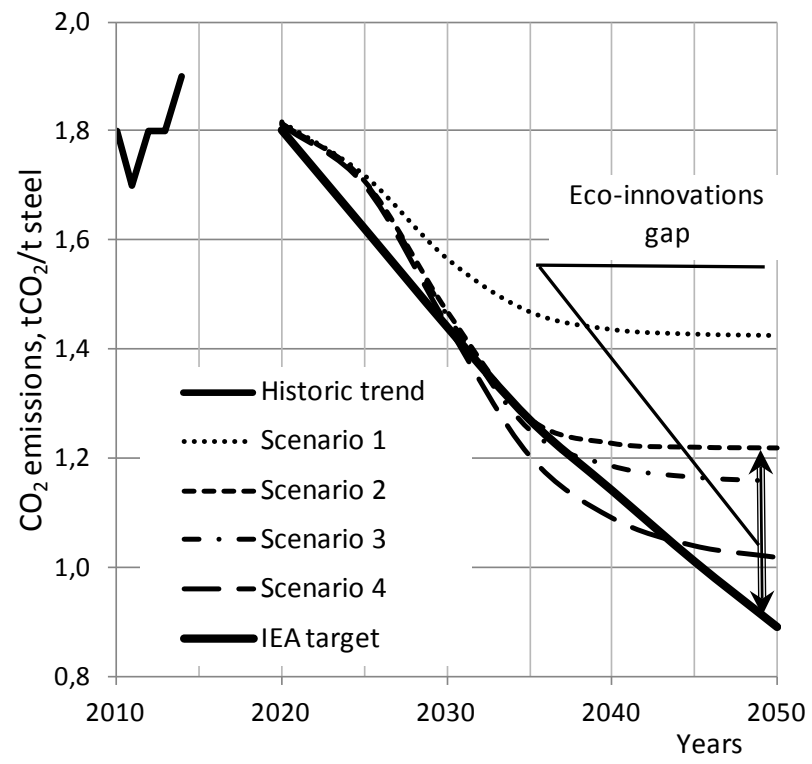

Fig. 4 Historic trend, IE $A$ target and modelling of $\mathrm{CO} 2$ emissions in our scenarios

The results of modelling show that presently there is no technology capable of bringing the iron and steel industry to the sustainable pathway outlined by the IEA and an ecoinnovation gap is obvious from Fig 4.

Excess of $\mathrm{CO}_{2}$ emissions over the IEA target in four scenarios is shown in Fig. 5. To estimate the total quantity of $\mathrm{CO}_{2}$ emitted to the atmosphere over the IEA threshold, the curves shown in Fig 5 were approximated using $4^{\text {th }}$ degree polynomials. Definite integral of these polynomials gives the area of respected curved trapezoids that is equal to the aggregate excess amount. Total amounts of $\mathrm{CO}_{2}$ emitted in excess of the IEA 
target during 30 years are shown for each scenario in Fig 6. Large scale deployment of the innovative ironmaking technologies coupled with increased share of secondary steel production and deployment of the BATs in Scenario 4 enables reducing of the excessive $\mathrm{CO}_{2}$ emissions by $94 \%$ compared to Scenario 1 where only the BATs are deployed.

Obviously, implementation of Scenario 4 might be constrained by many factors such as lack of financial resource, unsuccessful commercialisation, limited technology transfer, lack of control over the capacities to be built in the developing countries despite availability of unutilised capacities in the developed world etc.

After its launch a blast furnace operates for 25 years as average with few stops for repair. Therefore, to accomplish even Scenario 3, the mindset of investors shall change within next 10 years in order to give up erecting very reliable and proven blast furnaces in favour of unusual innovative technologies. And it is very unclear whether planned timeline for demonstration of innovative technologies will be respected and the results will be convincing enough for making this behavioural change happen.

Global steel market is increasingly competitive under current economic conditions: unutilised steelmaking capacities in China only exceed total production of steel in Japan and Russia taken together. Collaboration of competitors for development of HIsarna indicates that the cost of bringing such a technology to the market is too high for any company or even for a country to take it on its own. Further enhancing of international cross-company collaboration is needed to facilitate development and commercialisation of eco-innovations.

Currently steelmakers operate in a narrow profit margin; therefore international instruments (e.g. flexible mechanisms of the Kyoto Protocol such as Clean Development Mechanism, Emission Trading and Joint Implementation (UNFCCC, 2016)) shall be further applied in order to deliver an incentive for modernisation, to boost the carbon investment and to ensure the technology transfer. Essential role shall play appropriate carbon tax policy, notably by affecting the future industrial infrastructure (van Ruijven et al, 2016).

In any scenario, reaching of the IEA targets requires large scale deployment of CCS/CCU technologies that are still on early development phase and might be challenged by social acceptance because their effect of CCS on the environment still unknown, whereas market demand for carbon dioxide is too low. 2DS envisages capturing $40 \%$ of $\mathrm{CO}_{2}$ emissions in iron and steel industry (IEA, 2014) that is generally consistent with our modelling. 


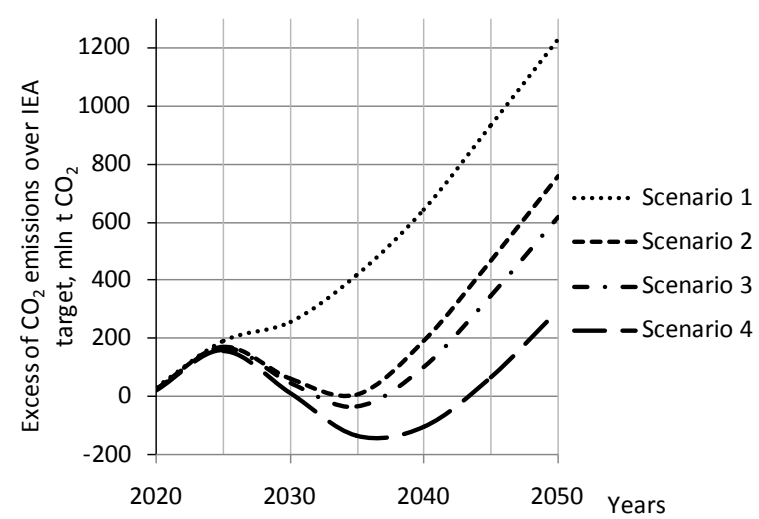

Fig. 5 Excess of $\mathrm{CO}_{2}$ emissions over the IE $A$ target in four scenarios

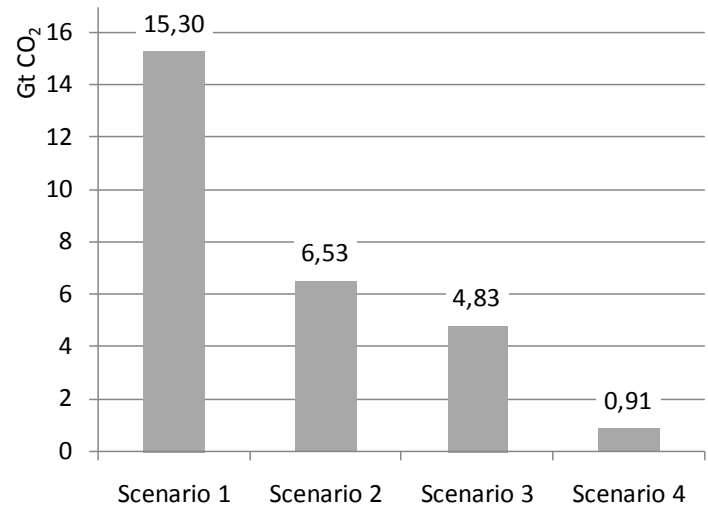

Fig 6 Amounts of $\mathrm{CO}_{2}$ emitted by the iron and steel industry in excess to the IE $A$ targets during 30 years from 2020 to 2050

Bridging of the eco-innovation gap is possible if some disruptive breakthrough technologies with nearly zero $\mathrm{CO}_{2}$ emissions will be invented, rapidly developed and brought to the market before 2050. Some promising projects can be mentioned, such as ULCOLYSIS (developed in frames of EU ULCOS project) (Wins, 2012) and the Molten Oxyde Electrolysis process developed in the US (Allanore et al, 2013), where electric potential is used to separate iron and oxygen in molten electrolyte producing liquid iron and oxygen gas. However, easily applicable to produce aluminium, in case of iron, electrolysis faces a number of challenges such as stability of anode material and reoxidation of reduced liquid iron. Currently these processes are on fundamental research phase; moreover, they are sensible only if the electricity source is fully decarbonised, hence a timeline for bringing them even to demonstration phase is unclear.

Several hydrogen-based ironmaking technologies are under development worldwide, being another near zero carbon candidates. E.g. in the Flash Ironmaking Process developed by the University of Utah in collaboration with several industrial companies, if hydrogen is used as a reductant, $\mathrm{CO}_{2}$ emissions will be decreased by $96 \%$ compared to blast furnace (Chen et al, 2015). Currently this technology is on the phase of 
fundamental laboratory experiments. High cost of hydrogen is mentioned by the developers as the major barrier. Some undisclosed hydrogen ironmaking technologies are also part of Japanese COURSE50 project (Tonomura, 2013).

Development of technologies to produce hydrogen is strongly focused by researchers worldwide; however, a technology for large scale production of affordable hydrogen with very low $\mathrm{CO}_{2}$ emissions has yet to be developed. Other barriers such as transportation and storage of hydrogen in large quantities shall also be overcome (Shatokha et al, 2016); therefore use of hydrogen for metal smelting is considered by the Intergovernmental Panel for Climate Change as a longer-term option, capable to enter the marketplace only beyond 2030 (IPCC, 2007).

\section{Conclusions}

1. Rapid and radical modernisation of the iron and steel industry is indispensable for reducing the anthropogenic GHG emissions to the levels required for keeping the global warming within $2^{\circ} \mathrm{C}$.

2. Large scale deployment of the BAT might be essential for cutting $\mathrm{CO}_{2}$ emissions in some individual countries; however, globally, it will not be sufficient for reaching climate change mitigation targets even if coupled with increased production of the recycled steel using largely decarbonised electricity.

3. If some alternative ironmaking processes will be brought by 2020 to the technology readiness level required for commercialisation, it allows for reaching emissions level consistent with the IEA targets by 2030-2040, subject to market penetration. However, presently there is no technology enabling aligning emissions with the sustainability targets during 2040-2050. Bridging of this eco-innovation gap requires either development of breakthrough technology to produce steel with very low carbon footprint or large scale deployment of CCS/CCU technologies. Enhanced material efficiency is also very essential for reducing the global steel demand.

5. International instruments shall be applied in order to deliver incentive for modernisation, to boost carbon investment mechanisms and to ensure smooth borderless technology transfer. International collaboration is needed to facilitate development and commercialisation of eco-innovations.

\section{Acknowledgements}

This work is partially supported by EUClim project 564689-EPP-1-2015-1UAEPPJMO-MODULE funded by the EU under Erasmus+ Programme (http://euclim.com/).

\section{References}

Allanore, A., Yin, K., Sadoway, D.R. (2013) A new anode material for oxygen evolution in molten oxide electrolysis. Nature (497), 353-356

Chen, F., Mohassab, Y., Jiang, T., Sohn H.Y. (2015) Hydrogen Reduction Kinetics of Hematite Concentrate Particles Relevant to a Novel Flash Ironmaking Process. Metallurgical and Materials Transactions B. 46 (3), 1133-1145 
Croezen, H., Korteland, M. (2010). Technological developments in Europe: A long-term view of $\mathrm{CO}_{2}$ efficient manufacturing in the European region. Commissioned by Climate Action Network Europe, CE Delft

European Commission (2015) Environment Council approves the EU's intended nationally determined contribution to the new global climate agreement. http://ec.europa.eu/clima/news/articles/news_2015030601_en.htm (11.05.2016)

Gutowski, T. G., Sahni, S., Allwood, J.M., Ashby, M.F., Worrell, E. (2013) The energy required to produce materials: constraints on energy-intensity improvements, parameters of demand. Phil. Trans. R. Soc. A. 371, 20120003. http://rsta.royalsocietypublishing.org/content/371/1986/20120003 (11.05.2016)

IEA (2014). Energy Technology Perspectives: Harnessing Electricity's Potential. OECD/IEA, Paris

IPCC (2007). IPCC Fourth Assessment Report: Climate Change (2007). 7.12.1 Longer-term mitigation options. https://www.ipcc.ch/publications_and_data/ar4/wg3/en/ch7s7-12.html. (11.05.2016)

Krabbe, O., Linthorst, G., Blok, K., Crijns-Graus, W., van Vuuren, D. P., Höhne, N., Faria, P., Aden, N., Pineda, A.C. (2015). Aligning corporate greenhouse-gas emissions targets with climate goals. Nature Climate Change (5), 1057-1060

Meijer, K., Zeilstra, C., Treadgold, C., van der Stel, J., Peeters, T., Borlée, J., Skorianz, M., Feilmayr, C, Goedert. P, Dry, R (2015). The HIsarna ironmaking process. METEC \& $2^{\text {nd }}$ ESTAD, Düsseldorf, 15-19 June 2015

Pauliuk, S., Milford, R.L., Müller, D. B., Allwood, J. M. (2013). The steel scrap age. Environ Sci Technol. (47), 3448-3454

Rio Tinto (2016). HIsmelt process. http://www.riotinto.com/ironore/hismelt-process-10659.aspx (11.05.2016)

Shatokha, V., Sokur, I., Kamkina, L. (2016). Study on Water Splitting Potential of Some Metallurgical Wastes for Production of Hydrogen. J. Sustain. Metall. (2), 116-122

Tonomura, S. (2013) Outline of Course 50. Energy Procedia (37), 7160-7167

ULCOS (2014). ULCOS top gas recycling blast furnace process. Final Report. European Commission, EUR 26414. http://bookshop.europa.eu/en/ulcos-top-gas-recycling-blast-furnace-process-ulcos-tgrbf-pbKINA26414/ (11.05.2016)

UNFCCC (2016). The Mechanisms under the Kyoto Protocol: Emissions Trading, the Clean Development Mechanism and Joint Implementation. http://unfccc.int/kyoto_protocol/mechanisms/items/1673.php. (11.05.2016)

van der Stel, J. (2013). Top gas recycling blast furnace developments for 'green' and sustainable ironmaking. Ironmaking and Steelmaking (40), 483-489

van Ruijven, B.J., van Vuuren, D.P, Boskaljon, W, Neelis, M.L., Saygin, D., Patel M.K. (2016). Long-term model-based projections of energy use and $\mathrm{CO}_{2}$ emissions from the global steel and cement industries. Resources, Conservation and Recycling. (112), 15-36

Wins, T (2012). The Low Carbon Future of the European Steel Sector: Presentation for the EU Parliament. September http://ccap.org/resource/the-low-carbon-future-of-the-european-steel-sector $(11.05 .2016)$

Worldsteel (2014). Sustainability indicators. https://www.worldsteel.org/statistics/Sustainabilityindicators.html (11.05.2016)

Worldsteel (2015) Steel's contribution to a low carbon future and climate resilient societies. Worldsteel position paper. https://www.worldsteel.org/publications/position-papers/Steel-s-contribution-toa-low-carbon-future.html (11.05.2016)

Yi, S-H., Lee, H-G. (2015) The Recent Update of Innovative Ironmaking Process FINEX. 2nd Intl Conf. Advances in Metallurgical Processes \& Materials, Kyiv, June 04-05, 2015 